Filol. Linguíst. Port., São Paulo, v. 17, n. 1, p. 249-272, jan./jun. 2015 http://dx.doi.org/10.11606/issn.2176-9419.v17i1p249-272

\title{
A oralidade em sala de aula de língua portuguesa: o que dizem os professores do ensino básico
}

\author{
Orality in the Portuguese language classroom: what \\ elementary school teachers are saying
}

\author{
Marise Adriana Mamede Galvão* \\ Josilete Alves Moreira de Azevedo ** \\ Universidade Federal do Rio Grande do Norte, Currais \\ Novos, Rio Grande do Norte, Brasil
}

Resumo: Esta pesquisa teve como foco central uma discussão acerca da
modalidade oral e ensino de Língua Portuguesa no nível fundamental de
escolarização. Como ponto de partida, ressaltamos a necessidade de os
indivíduos desenvolverem competências linguístico-discursivas por meio
de diferentes gêneros de textos nas interaçóes da vida cotidiana, tanto
nas mais espontâneas quanto nas mais ritualizadas. Buscamos, assim,
contribuir com o conhecimento acadêmico-científico na direçáo de que
aos alunos do ensino básico sejam dadas oportunidades de produzir tex-
tos orais quer sejam em interaçóes informais, quer sejam naquelas com
maior controle e regulação na produçáo e recepção. Orientamo-nos pela
questão: os textos orais estâo sendo utilizados como objeto de ensino no
desenvolvimento das práticas comunicativas dos alunos em sala de aula?
Definimos, como objetivo, investigar acerca da oralidade em sala de aula
de Língua Portuguesa com o propósito de descrever, analisar e interpretar

* Professora Associada, lotada no Departamento de Letras do CERES, faz parte do corpo docente do Mestrado Profissional em Letras e do Programa de Pós-Graduação em Estudos da Linguagem PpgEL da Universidade Federal do Rio Grande do Norte - UFRN, Currais Novos, Rio Grande do Norte, Brasil; marisemamede@gmail.com

** Professora Associada, lotada no Departamento de Letras do CERES; faz parte do corpo docente do PROFLETRAS da Universidade Federal do Rio Grande do Norte - UFRN, Currais Novos, Rio Grande do Norte, Brasil; josileteazevedo@yahoo.com.br 
o que dizem os docentes acerca do ensino, identificando as concepçóes de oralidade apontadas por eles e os gêneros textuais orais constitutivos das atividades didáticas propostas em sala de aula. Adotando os postulados da pesquisa qualitativa, buscamos interpretar questóes específicas do dizer de professores por meio de 12 entrevistas semiestruturadas, gravadas (em áudio) e posteriormente transcritas. Baseamo-nos teoricamente, entre outros, nos trabalhos de Marcuschi (1986, 2001a e 2001b, 2002, 2005); Castilho (1998); Fávero, Andrade e Aquino (1999); Schneuwly, Dolz e colaboradores (2004); Cavalcante e Teixeira (2007); Gomes-Santos (2012); Leal e Gois (2012). As análises dos dados revelaram que os docentes ainda não têm clareza das noçôes teóricas sobre a oralidade que os possibilitem realizar açóes didáticas canalizadas para a formação de alunos linguisticamente competentes. Dessa forma, no trabalho com a oralidade, os professores precisam privilegiar os aspectos linguísticos, extralinguísiticos, paralinguísticos e cinésicos, propiciando aos alunos vivências em atividades pedagógicas que lhe sirvam de subsídios nas práticas sociais da vida cotidiana.

Palavras-chave: Oralidade. Ensino. Língua Portuguesa.

Abstract: The central focus of this study is a discussion on oral production in the teaching of Portuguese Language and Language Arts classes at the elementary school age level. We begin with the premise that individuals need to develop discursive-linguistic competencies through different oral genres that are a part of the interactions of daily life - from the most spontaneous to most highly ritualized. Our goal is to contribute to the academic-scientific scholarship on providing elementary school students with opportunities for oral production, whether in informal interactions or those that are highly controlled and regulated from the perspective of both production and reception. Our guiding question is: are oral texts being used as teaching objects in the development of students' communicative practices in the classroom? Our objective is to investigate orality in the Portuguese language classroom, aiming to describe, analyze and interpret what teachers say about the teaching process, identifying the concepts of orality that they identify and the oral genres that comprise the didactic activities proposed in the classroom. Adopting a qualitative research model, we aim to interpret specific questions from teachers' responses gathered in 12 semi-structured interviews, recorded in audio and transcribed. Our theoretical framework is based on the following researcher, among others: Marcuschi (1986, 2001a, and 2001b, 2002, 
2005); Castilho (1998); Fávero, Andrade and Aquino (1999); Schneuwly, Dolz and collaborators (2004); Cavalcante and Teixeira (2007); Gomes-Santos (2012); Leal and Gois (2012). The analysis of the data reveals that the teachers are still not clear about notions of orality that enable them to carry out didactic activities directed to educating students in linguistic competence. In this way, working with orality, teachers need to prioritize linguistic, extra-linguistic, paralinguistic and synesthetic aspects, providing students with experiences in pedagogical activities that give them tools they can use in social practices of daily life.

Keywords: Orality. Teaching. Portuguese Language.

\section{CONSIDERAÇÓES INICIAIS}

Discussóes em torno das modalidades oral e escrita da língua, no que concerne aos aspectos da relação fala e escrita, gêneros textuais orais, oralidade e ensino, entre outras questôes, têm sido foco de interesse dos trabalhos de Marcuschi (1986, 2001a e 2001b, 2002, 2005); Castilho (1998); Fávero, Andrade e Aquino (1999); Schneuwly, Dolz e colaboradores (2004); Cavalvante e Teixeira (2007); Gomes-Santos (2012), além de uma série de reflexôes sobre o texto falado como objeto de ensino, publicadas em um livro organizado por Leal e Gois (2012). Essas pesquisas trazem à tona as preocupaçóes de estudiosos com noçôes e conceitos sobre práticas sociais, seja com relação aos diferentes espaços e em atividades de realização destas, seja no tocante ao ensino e aprendizagem de gêneros orais.

Nessa direção, importa ressaltar uma questão central para os estudiosos: a necessidade de os indivíduos desenvolverem competências linguístico-discursivas por meio de diferentes gêneros de textos nas interaçôes da vida cotidiana, sejam elas mais espontâneas (como nas interações casuais), ou mais ritualizadas (como nas interaçôes institucionalizadas). Essa necessidade é justificada por termos em mente que as pessoas tornam-se sujeitos críticos e aptos para agirem em seu meio, a partir dessas interaçóes e dos lugares sociais diversificados, que as possibilitam falar - assumindo uma determinada posição - argumentar, concordar, discordar, desempenhando papéis a cada momento da vida cotidiana.

Assim sendo, esta reflexão tem como preocupaçáo central promover um espaço de discussão em torno da oralidade e ensino de Língua Portuguesa, buscando contribuir com o conhecimento acadêmico-científico na direção de que aos alunos do ensino básico sejam dadas oportunidades de produzir textos orais. Ressaltamos, nesse sentido, a necessidade de aquisição de conhecimentos 
referentes às especificidades de gêneros informais, como conversas espontâneas e as de gêneros que exijam maior controle e regulação, como os debates regrados, as entrevistas, os relatos, os seminários, entre outros.

Tendo essa temática como ponto de partida, procuramos discutir sobre o espaço da oralidade em sala de aula de Língua Portuguesa e a pergunta que nos orientou foi: os textos orais estão sendo utilizados como objeto de ensino no desenvolvimento das práticas comunicativas dos alunos em sala de aula? A partir dessa questão, de âmbito mais geral de nossa investigação, duas outras indagaçôes constituíram-se como desdobramentos, a saber: qual a concepção do professor sobre a oralidade? Que atividades pedagógicas são desenvolvidas no trabalho com textos orais em sala de aula?

Nessa ótica, traçamos como objetivo geral investigar acerca da oralidade em sala de aula de Língua Portuguesa e, do ponto de vista específico, estabelecemos neste trabalho: descrever, analisar e interpretar o que dizem os docentes acerca do ensino da oralidade, identificando as concepçóes de oralidade apontadas por eles; que gêneros textuais orais são constitutivos das atividades didáticas propostas pelo professor em sala de aula, visando o desenvolvimento das competências linguístico-discursivas dos alunos, direcionadas às práticas sociais orais.

Do ponto de vista metodológico, esta investigação seguiu os postulados da pesquisa qualitativa, buscando a interpretação de questóes específicas do dizer de professores do ensino básico, a partir das quais pudemos fazer generalizaçóes em torno do objeto discutido. Para tanto, o corpus constitutivo desta investigação foi formado por 12 entrevistas semiestruturadas, realizadas com professores da rede pública de ensino, gravadas (em áudio) e posteriormente transcritas, conforme as orientaçóes propostas por Marcuschi (1986), contendo as seguintes indagaçóes: Que gêneros orais são priorizados em sua prática pedagógica? Quais as estratégias que emprega para trabalhar o texto oral? Quais os elementos da organização do texto oral são explicitados no estudo da coesão e a coerência do texto falado? Como é trabalhada a relação fala / escrita? Que tipo de atividade desenvolve para favorecer a compreensão dos alunos com relação às especificidades do texto oral em relação à escrita?

Para a consecução desta proposta, segmentamos o trabalho nas seguintes seçóes: inicialmente, refletimos sobre oralidade, ressaltando as noçôes e aspectos inerentes a essa prática social; a seguir, tecemos consideraçóes sobre tratamento da oralidade no ensino; na sequência, analisamos os dados à luz das questóes teóricas e apresentamos algumas conclusóes. 


\section{NOÇÓES DE ORALIDADE}

Primeiramente, fizemos um diálogo com as consideraçóes de alguns autores que discutem a oralidade, a partir das reflexôes situadas ao longo de um determinado período de tempo. Castilho (1998, p. 16), em livro dedicado à língua falada, deixa claro que a língua falada é uma modalidade em que "os usuários estão em presença", sendo as coordenadas espaço-temporais evidenciadas na própria situação de interlocução. Nessa direção, o autor aponta algumas características da língua falada, entre estas as que são geradas pela organização de turnos, pelo sistema de correção e reparo, bem como pelo uso de marcadores conversacionais, haja vista que o texto é produzido em coautoria, daí observarmos o planejamento e execução simultâneos.

No trabalho que realizaram sobre Oralidade e Escrita, Fávero, Andrade e Aquino (1999, p. 21) salientam que, "a produção de um texto falado corresponde a uma atividade social que requer a coordenação de esforços de pelo menos dois indivíduos que têm algum objetivo comum.”. Nesse sentido, compreendemos que textos falados são produzidos em eventos de comunicação, que podem ser formais e informais, com graus diferentes de preparo, sendo influenciados pela relação entre participantes, o canal usado e outras especificidades. Assim sendo, os textos por meio dos quais interagimos sofrem as coerções das diversas interações em nossas práticas sociais do dia a dia, sejam elas mais ou menos espontâneas, sejam mais ou menos formais.

A pesquisa de Marcuschi (2001, p. 16) focaliza a temática de língua e texto em um conjunto de práticas sociais, defendendo um posicionamento de que "as línguas se fundamentam em usos". Salienta o autor que, "oralidade e escrita são práticas e usos da língua com características próprias [...]”. Dessa forma, podemos entender que essas duas modalidades "permitem a construção de textos coesos e coerentes, ambas permitem a elaboração de raciocínios abstratos e exposições formais e informais, variações estilísticas, sociais, dialetais e assim por diante." (Marcuschi, 2001, p. 17). Salientando o ponto de vista desse pesquisador, tanto a oralidade quanto a escrita são imprescindíveis na nossa vida, tendo em vista os vários contextos de uso, seja na esfera burocrática, na família, na escola, entre outros.

Nessa direção, a observação feita por Marcuschi (2001, p. 25) com relação às práticas sociais torna-se relevante para compreender a questáo central deste estudo. A oralidade é definida como "prática social interativa para fins comunicativos que se apresenta sob variadas formas ou gêneros textuais fundados na realidade sonora; ela vai desde uma realização mais informal à mais formal nos mais variados contextos de uso". Essas afirmaçóes implicam que produzimos textos 
orais em conversações, nas participações em debates, seminários, conferências, aulas, para citar alguns gêneros, com maior ou menor grau de planejamento, formalidade, todos estes caracterizados como práticas orais.

Tendo como horizonte essas considerações, a seguir discutimos a oralidade e ensino de Língua Portuguesa, a partir das pesquisas de alguns autores.

\section{ORALIDADE E ENSINO}

Sabemos que há uma compreensão generalizada de que a oralidade tem um relevante papel no ensino de língua materna, sendo, inclusive, uma das orientaçôes contidas nos Parâmetros Curriculares Nacionais. Dessa forma, destacamos nas seçôes a seguir, a oralidade na relação fala e escrita, como objeto de ensino, na proposta educacional vigente $(\mathrm{PCN})$.

\subsection{Na relação fala e escrita}

Marcuschi (2005) faz referências acerca do uso principal da fala nas atividades no dia a dia, embora as instituições escolares, ainda, não lhe deem a devida atenção, se comparada com as atividades realizadas na modalidade escrita. Assim, o autor salienta a necessidade de se ter uma preocupação também com o lugar e o papel da oralidade no ensino de língua. Nesse aspecto, o autor esclarece que:

Certamente, não se trata de ensinar a falar. Trata-se de identificar a imensa riqueza e variedade de usos da língua. Talvez, a melhor maneira de determinar o lugar do estudo da fala em sala de aula seja especificando os aspectos nos quais um tal estudo tem a contribuir (Marcuschi, 2005, p. 24).

Nessa perspectiva, o pesquisador destaca alguns aspectos centrais no estudo da fala, entre estes a variação, argumentando que a língua falada é variada, sendo importante ao aluno ter consciência de noções como sotaque, variante, gíria, dialeto, entre outras. $\mathrm{O}$ autor também salienta a possibilidade de se analisar os níveis da língua, com relação às formas de realização, desde as mais espontâneas até as mais formais, tanto na oralidade quanto na escrita. Ele ressalta, ainda, que não se trata de uma atenção apenas com o léxico, mas também com questões relacionadas à polidez, aos aspectos interpessoais, às relaçóes culturais, entre outros que podem servir de exemplos na própria sala de aula. 
Merece destacarmos, também, "que não se trata de transformar a fala em um tipo de conteúdo autônomo no ensino de língua: ela tem de ser vista integradamente e na relação com a escrita. Por isso, é necessário ter clareza quanto ao papel deste tipo de trabalho." (Marcuschi, 2005, p. 25).

Nesse sentido, o autor lembra-nos que um exemplo do estudo da oralidade, em uma perspectiva mais ampla, é a observação das relaçóes desta com a escrita, algumas semelhantes e outras diferenciadas. Além disso, chama a atenção para a contribuição da oralidade no processo de formação cultural, preservação das tradiçốes, entre outras possibilidades.

Para que possamos analisar os dados do corpus por nós constituído, abordamos a questão da oralidade como objeto de ensino.

\subsection{Como objeto de ensino}

As pesquisadoras Cavalcante e Melo (2007, p. 93) pautam-se nas consideraçóes de Marcuschi (2001), compartilhando com aquele autor a visão de que oralidade e a escrita são duas práticas sociais de uso da língua, consideradas como formas de manifestação textual, sendo ambas normatizadas. Assim, assumindo uma postura que desfaz a superioridade da escrita sobre a oralidade, as autoras indagam sobre o campo de atuação da oralidade na escola e fazem as seguintes perguntas: "que gêneros abordar no tratamento da oralidade? Como tratar das estratégias textuais nos gêneros orais, levando em consideração as peculiaridades da modalidade oral e dos gêneros em si? E que gêneros privilegiar nesse trabalho?”.

A partir dessas indagações, as estudiosas salientam que, inicialmente, deve-se ter clareza acerca do gênero oral a ser ensinado, no que se refere às características constitutivas e de que maneira os aspectos inerentes a estes podem ser tomados como objetos no ensino e aprendizagem de Língua Portuguesa. Nesse sentido, Cavalcante e Melo (2007) apresentam quadros sistematizados para salientar alguns aspectos de natureza extralinguística, paralinguística e linguística que podem ser observados em gêneros orais e ser explorados em sala de aula, os quais transcrevemos, a seguir, no quadrol, adaptado pelas autoras de um quadro apresentado por Marcuschi (2002): 


\begin{tabular}{|l|l|}
\hline a) Grau de publicidade & $\begin{array}{l}\text { número de participantes (produtores e receptores) ou } \\
\text { tamanho do público envolvido na situação comunicativa; }\end{array}$ \\
\hline $\begin{array}{l}\text { b) Grau de intimidade dos } \\
\text { participantes }\end{array}$ & $\begin{array}{l}\text { conhecimento entre os participantes; } \\
\text { conhecimentos partilhados, grau de institucionalização do } \\
\text { evento; }\end{array}$ \\
\hline $\begin{array}{l}\text { c) Grau da participação } \\
\text { emocional }\end{array}$ & $\begin{array}{l}\text { afetividade, relacionamento na situação, emocionalidade e } \\
\text { expressividade; }\end{array}$ \\
\hline $\begin{array}{l}\text { d) Proximidade física dos } \\
\text { parceiros de comunicação }\end{array}$ & $\begin{array}{l}\text { comunicaçáo face a face, distanciada, no mesmo tempo ou } \\
\text { em tempos diversos; }\end{array}$ \\
\hline e) Grau de cooperação & $\begin{array}{l}\text { possibilidade de atuaçáo direta no evento, tal como no } \\
\text { diálogo ou num texto monologado ou produzido à distância; }\end{array}$ \\
\hline f) Grau de espontaneidade & comunicação preparada previamente ou não; \\
\hline g) Fixação temática & $\begin{array}{l}\text { o tema é ou não fixado com antecedência; o tema é } \\
\text { espontâneo; }\end{array}$ \\
\hline
\end{tabular}

Quadro 1. Aspectos extralinguísticos.

Fonte: Cavalcante e Melo (2007, p. 93-94)

Este quadro revela que diferentes gêneros da oralidade apresentam características ou aspectos que podem ser encontrados em maior ou menor grau em cada um deles. Para exemplificar, as autoras tomam por base a conversa e a palestra. Uma palestra faz parte do gênero público, enquanto a conversa pertence ao privado; na palestra, o conhecimento dos participantes é partilhado; na conversa, é íntimo. Além disso, na palestra, a possibilidade de participação na produção textual é baixa, assim como a espontaneidade; na conversa, a produção textual é de natureza interativa, a dialogicidade é observada na troca de falantes, apresenta alta espontaneidade, forte participação emocional e afetiva, apresentando liberdade quanto ao tema; enquanto isso, a palestra é monológica, sendo o tema previamente fixado.

O quadro 2, a seguir, cujo foco traz os aspectos paralinguísticos e cinésicos, tomando por base a proposta de Schneuwly e Dolz (2004). 


\begin{tabular}{|l|l|}
\hline \multicolumn{1}{|c|}{ Fenômeno } & \multicolumn{1}{c|}{ Características } \\
\hline Aspectos paralinguísticos & $\begin{array}{l}\text { Qualidade de voz (aguda, rouca, grave, sussurrada, } \\
\text { infantilizada) } \\
\text { Elocução e pausas } \\
\text { Risos/suspiros/choro/irritação }\end{array}$ \\
\hline \multirow{3}{*}{ Aspectos cinésicos } & $\begin{array}{l}\text { Atitudes corporais (postura variada: ereta, inclinada, etc.). } \\
\text { Gestos (mexer com as mãos, gestos ritualizados, como acenar, } \\
\text { apontar, chamar, fazer sinal de ruim, de bom, etc.) } \\
\text { Troca de olhares } \\
\text { Mímicas faciais }\end{array}$ \\
\hline
\end{tabular}

Quadro 2. Aspectos paralinguísticos e cinésicos. Fonte: Cavalcante e Melo (2007, p. 95)

A observação que fazemos é que esses aspectos ressaltados por Cavalcante e Melo (2007) podem ser identificados nos gêneros orais em maior ou menor escala, dependendo se ocorrem em espaços de mais ou menos informalidade, conforme a situação de interação. Assim, são relevantes para as análises e reflexóes em sala de aula de língua materna.

O quadro 3, a seguir, apresentado pelas pesquisadoras reúne os aspectos linguísticos característicos dos gêneros orais, adaptado de Schneuwly; Dolz et al. (2004). 


\begin{tabular}{|c|c|}
\hline Fenômeno & Características \\
\hline Marcadores Conversacionais & $\begin{array}{l}\text { Sáo marcadores típicos da interação oral, para indicar que } \\
\text { o interlocutor está prestando atençáo; para marcar o turno, } \\
\text { etc. Podem vir no início, meio e final de turno. Exemplos: } t a ́ \text {, } \\
\text { hum, sim, aí, aham. }\end{array}$ \\
\hline Repetições e paráfrases & $\begin{array}{l}\text { Duplicação de algo que veio antes; assim como as repetiçôes, } \\
\text { também as paráfrases refazem algo vindo antes. }\end{array}$ \\
\hline Correções & $\begin{array}{l}\text { Há a substituição de algo que é retirado. Há a correção de } \\
\text { fenômenos lexicais, sintáticos e reparos de problemas intera- } \\
\text { cionais. }\end{array}$ \\
\hline Hesitações & $\begin{array}{l}\text { Demonstram tentativas de organizar o discurso oral ou } \\
\text { podem caracterizar também insegurança do locutor. Vêm } \\
\text { no início de um novo tópico ou antes de um item lexical. } \\
\text { Exemplos: ééé::; ááá::. }\end{array}$ \\
\hline Digressóes & $\begin{array}{l}\text { As digressóes são uma suspensão temporária de um tópico } \\
\text { que retorna. Apontam para algo externo ao que se acha em } \\
\text { andamento }\end{array}$ \\
\hline $\begin{array}{l}\text { Expressões formulaicas, } \\
\text { expressões prontas }\end{array}$ & $\begin{array}{l}\text { Exemplos: provérbios, lugares comuns, expressóes feitas, } \\
\text { rotinas. Não têm um funcionamento orientado para frente } \\
\text { ou para trás, mas para a contextualidade e para o conteúdo. } \\
\text { Exemplo: bom dia, até logo. }\end{array}$ \\
\hline $\begin{array}{l}\text { Atos de fala/Estratégias de } \\
\text { polidez positiva e negativa }\end{array}$ & $\begin{array}{l}\text { Atos de fala positivos, tais como elogiar, agradecer, aceitar, } \\
\text { etc. } \\
\text { Atos de fala negativos, tais como discordar, recusar, ofender, } \\
\text { xingar, etc. }\end{array}$ \\
\hline
\end{tabular}

Quadro 3. Aspectos linguísticos.

Fonte: Cavalcante e Melo (2007, p. 95-96)

Como podemos constatar, os fenômenos linguísticos elencados no quadro 3 podem ser explorados e alguns priorizados em sala de aula, a partir dos gêneros orais selecionados para o trabalho pedagógico.

\subsection{Na proposta educacional vigente (PCN)}

A oralidade como objeto de ensino é o foco da reflexão de Leal, Brandão e Lima (2012, p. 15). Nesse aspecto, elas ressaltam que "não somente os textos escritos são construídos com base nos conhecimentos ativados pela adoção de um gênero. Os textos orais também o são". Assim sendo, elas pontuam a noção bakhtiniana de gênero do discurso, objetivando situar que os gêneros orais possuem 
regularidades e que autores, como Dolz e Schneuwly (2004), postulam a necessidade de incluí-los como objetos de ensino na escola. Partindo desse direcionamento, as pesquisadoras buscam o que as propostas curriculares, materiais didáticos e pesquisas discutem acerca do tema, apontando a necessidade de se definir objetivos didáticos explícitos relativos a, pelo menos, quatro dimensôes que envolvem o desenvolvimento da linguagem oral. São elas:

- $\quad$ valorização de textos da tradição oral;

- $\quad$ oralização do texto escrito;

- variação linguística e relaçôes entre fala e escrita;

- $\quad$ produção e compreensão de gêneros orais; (Leal; Brandão; Lima, 2012, p. 16).

No que se refere à valorização de textos de tradição oral, as autoras enfatizam a importância da linguagem na construção e manutenção das diferentes expressóes da cultura da comunidade e do país, a partir dos conhecimentos transmitidos nas interaçóes orais pelas gerações mais velhas às mais novas. Como exemplos de interaçóes nesse aspecto, os discentes podem pesquisar sobre receitas culinárias, remédios utilizados pelas geraçóes passadas, contos, brincadeiras, entre tantos outros textos de que fazem usos na vida cotidiana. Desse modo, é possível que textos que constituem um arquivo na memória sejam conhecidos e usados pela cadeia da oralidade.

Com relação à oralização do texto escrito, trata-se de uma dimensão do trabalho com a interseção entre os eixos da oralidade e da leitura, envolvendo o desenvolvimento da fluência desta e das habilidades comunicativas orais. As pesquisadoras citam os aspectos que são salientados por Dolz e Schneuwly (2004), entre estes os que envolvem a fala e a leitura em voz alta, destacando: altura da voz, velocidade, aspectos retóricos relevantes no trabalho com a audiência, gestualidade, entre outros. Elas destacam que a oralização da escrita envolve recursos das práticas de linguagem que podem ser ensinados na escola e salientam o papel destes recursos para a recitação de poesias, representaçóes teatrais, notícias televisivas, etc.

No tocante à variação linguística e às relaçōes entre a fala e a escrita, as autoras mencionam os trabalhos de Bagno (1998), Sgarbi (2008), para ressaltar que o eixo da oralidade vai além de um trabalho que discute a natureza dinâmica desta, para refletir também sobre o preconceito linguístico. Em atividades com esse foco, podemos analisar, junto com os alunos, descriçóes de textos, cujos participantes apresentem modos de falar diferentes, os fatores que ocasionaram 
essas diferenças, entre outras questóes. Além disso, é preciso refletir que não há um único modo de pensar, que as modalidades orais e escritas possuem suas regularidades, devendo, portanto, ser ensinadas, a fim de que os alunos possam compreender suas variações em contextos significativos de uso.

Em se tratando da produção e compreensão dos gêneros orais produzidos e escutados em atividades reais de interação estaria em foco um trabalho por meio de práticas que buscassem desenvolver

atitudes de respeito ao que o outro fala, monitoramento de seu próprio tempo da fala, escuta atenta ao que o outro diz, até conhecimentos e habilidades relativos à forma composicional de gêneros complexos, como seminários, notícias, orais ou debates regrados, ou mesmo conhecimentos relativos aos papéis desempenhados pelos envolvidos em uma situação de interação, como em um júri. (Leal; Brandão, Lima, 2012, p. 20).

Ressaltamos, assim, uma abordagem de ensino que enfatiza, também, a variação no que se refere à formalidade/informalidade dos gêneros, papéis interacionais das pessoas, relaçóes que estas assumem durante a interação, a partir da observação de gêneros mais espontâneos aos que ocorrem em maior escala nos espaços públicos e que demandam maior reflexão, planejamento, etc.

É de grande importância neste trabalho, discutir acerca do que estabelecem os documentos oficiais, no que se refere ao enfoque da oralidade no ensino de língua materna. Dizem os PCN (1998, p. 7-8 ) que um dos objetivos do ensino fundamental é:

utilizar as diferentes linguagens verbal, musical, matemática, gráfica, plástica e corporal como meio para produzir, gráfica, plástica e corporal como meio para produzir, expressar e comunicar suas ideias, interpretar e usufruir das produçôes culturais, em contextos públicos e privados, atendendo a diferentes intençôes e situaçóes de comunicação.

Observamos, nesse sentido, a preocupação com a modalidade oral da língua, seja em contextos de maior ou menor formalidade, haja vista as diferentes possibilidades de interaçóes e práticas sociais. Ademais, os parâmetros (1998, p. 24) pontuam que, em situaçôes de sala de aula, a linguagem oral vem sendo usada "unicamente como instrumento para permitir o tratamento dos diversos conteúdos". Sabemos que o espaço da sala de aula é o lugar de construção do 
conhecimento, possibilitando as trocas de opiniōes, de negociações de sentido e de avaliação pedagógica. Desse modo, os PCN chamam atenção para que o aluno se torne um cidadáo crítico, o que implica ser competente nas diferentes modalidades de uso da língua.

Nesse sentido, conforme é posto nos PCN (1998, p. 25):

Ainda que o espaço da sala de aula não seja um espaço privado, é um espaço público diferenciado: não implica, necessariamente, a interação com interlocutores que possam não compartilhar as mesmas referências (valores, conhecimento de mundo).

No entanto, nas inúmeras situaçóes sociais do exercício da cidadania que se colocam fora dos muros da escola a busca de serviços, as tarefas profissionais, os encontros institucionalizados, a defesa de seus direitos e opinióes os alunos serão avaliados (em outros termos, aceitos ou discriminados) à medida que forem capazes de responder a diferentes exigências de fala e de adequação às características próprias de diferentes gêneros do oral. Reduzir o tratamento da modalidade oral da linguagem a uma abordagem instrumental é insuficiente, pois, para capacitar os alunos a dominar a fala pública demandada por tais situaçōes.

Esse documento orienta, assim, que a escola propicie aos alunos o desenvolvimento de práticas da modalidade oral em diferentes situaçóes, entre estas as realizaçóes de entrevistas, de debates, de seminários, etc. Nesse aspecto, os PCN ressaltam:

Trata-se de propor situaçóes didáticas nas quais essas atividades façam sentido de fato, pois é descabido treinar um nível mais formal da fala, tomado como mais apropriado para todas as situaçóes. A aprendizagem de procedimentos apropriados de fala e de escuta, em contextos públicos, dificilmente ocorrerá se a escola não tomar para si a tarefa de promovê-la (PCN, 1998, p. 25).

Seguindo estas considerações teóricas, analisamos os dados dessa pesquisa, os quais revelam a concepção de ensino de oralidade nos contextos das salas de aula do nível fundamental. 


\section{A FALA DO PROFESSOR SOBRE ORALIDADE E ENSINO}

Sabemos que a inserção do texto oral como objeto de ensino tem sido consensual nas visões de pesquisadores da área de Língua Portuguesa, dos professores formadores, bem como dos docentes do ensino básico. Desse modo, podemos observar que a oralidade começa a marcar espaço nas atividades de ensino de Língua Materna, pois, como afirma Marcuschi (1986), a fala tem sua forma própria de organização, de desenvolvimento e de transmissão de informaçóes, o que nos permite tomá-la como uma modalidade específica das manifestaçóes da linguagem, inclusive por que ela é um status de desenvolvimento humano. Ou, ainda, como assevera Biber (1988, p. 8), que ela "precede as atividades de leitura e de escrita".

Todavia, no que se refere à transposição didática dos saberes sobre a oralidade, observamos que o trabalho com os textos permanece, parcialmente, distanciado das práticas pedagógicas realizadas no contexto das salas de aula, haja vista que muitos professores têm apresentado dificuldades para implementar estratégias metodológicas firmadas no objetivo de desenvolver a competência linguística da oralidade em seus alunos. Isso nos revela que, talvez, os docentes estejam perdendo de vista o perfil do aluno, a concepção interacional da linguagem, o objeto de ensino (textos orais e escritos), como também uma metodologia que permita a formação do cidadão crítico idealizado nas orientaçōes contidas na proposta oficial vigente.

Os PCN ressaltam a necessidade de se trabalhar a modalidade oral, uma vez que o aluno será avaliado no seu desempenho como falante, tendo que responder às diferentes exigências das situaçóes de fala, adequando-as aos gêneros orais e, especialmente, às situaçóes interacionais das quais participa. Logo, tal como explicita o referido documento, "Ensinar língua oral [...] significa desenvolver o domínio dos gêneros que apoiam a aprendizagem escolar de Língua Portuguesa e de outras áreas e, também, os gêneros da vida pública no sentido mais amplo do termo" (Brasil, 1998, p. 51).

Daí, a necessidade de se oportunizar aos alunos o convívio com textos orais, sugerindo tarefas que busquem mostrar a estrutura desses gêneros, levantar características típicas da fala, identificar aspectos linguísticos, extralinguísticos, paralinguísticos e cinésicos, transpor um texto oral para a modalidade escrita (retextualização), além de observar os graus de formalismo existentes e de usar as produçóes textuais dos próprios alunos. Assim, pressupomos que, ao trabalhar com a modalidade oral da língua, o professor deve partir de ações didáticas que garantam a realização de atividades sistemáticas de fala, escuta e reflexão, bem como observar os usos dos variados gêneros em contextos interacionais.

Nesse aspecto, constatamos que os professores entrevistados, ao serem questionados sobre "Que gêneros orais são priorizados?", explicitam em suas falas 
que reconhecem a importância de propor atividades com textos orais (debate, entrevista, seminário, relato, aula expositiva dialogada), tais como destacamos nos fragmentos 1,2 e 3 , a seguir:

\section{Fragmento 01 - Ent. 01}

bom $(+)$ a oralidade explorada em sala de aula $(+)$ acontece de váriasformas $(+)$ eh:: (+) com a leitura de alguns TEXTOS (+). Às vezes, em voz ALTA (+) distribuído (+) ao longo da turma. Uma pessoa lê cada / um parágrafo para cada pessoa $(+)$ existe também leitura da da:: produção escrita $(+)$ quando, às vezes, acontece $(++)$ às vezes eh::: apresentada eh:: feita a leitura em sala de AULA $(+)$ eh:: $(++)$ como o livro prioriza muito a parte

\section{Fragmento 02 - Ent. 11}

\section{debates e recontagem da leitura lida} leituras compartilhadas, debates a respeito dos assuntos abordados nos textos $(+)$ recontagem da leitura lida:::

além disso procuro mostrar a forma correta da colocação das palavras ou expressôes usadas de forma correta (+) através de correçôes ou do uso do dicionário

\section{Fragmento 03 - Ent. 06}

os gêneros orais que geralmente utilizo são os seguintes $(+)$ o debate formal e informal $(+)$ relato $(+)$ a entrevista $(+)$ o seminário $(+)$ e aula expositiva e (+) dialogada

A análise destas falas nos permite compreender, também, que há ênfase nas atividades de leitura (leitura em voz alta, recontagem da leitura, leitura compartilhada), o que nos faz constatar um entendimento reducionista do trabalho com a oralidade, uma vez que os docentes concebem-na como a vocalização do texto escrito, revelando que não há uma preocupação mais efetiva com o texto oral em sua essência, no qual seria priorizada a análise dos aspectos linguísticos, extralingústicos, paralinguísticos e cinésicos.

$\mathrm{Na}$ verdade, observamos certo equívoco teórico-metodológico, pois, quando distribuem com os alunos a leitura de parágrafos a serem lidos em voz alta, acreditam que estão realizando atividades com o texto oral, não se dando conta de que essa atitude foi apenas a seleção de uma metodologia de ensino de leitura que priorizou. 
Os docentes afirmaram que desenvolviam atividades com os gêneros próprios da oralidade, mas sabemos que promover debates, seminários, relatos, entrevistas, momentos de contação de histórias e rodas de conversas, dentre outros, sem a devida sistematização e planejamento não se caracteriza como uma ação didática satisfatória para a realização de atividades com o texto oral. É preciso entender que as práticas da oralidade devem ser encaminhadas mediante um trabalho intencionalmente organizado, no sentido de enfatizar aspectos dos gêneros orais na sua relação com a escrita, pois não é oportuno, nem suficiente que os alunos apenas conversem com o professor ou com os colegas sobre um determinado tema. No fragmento 04 , o professor prioriza a leitura e a roda de conversa, sem que tenhamos a explicitação de um planejamento sistemático destas atividades.

\section{Fragmento 04 - Ent. 08}

os gêneros orais que são priorizados na na sala de aula $(+)$ eh::

$(+)$ me utilizo MUIto de enquetes $(+)$ debates $(+)$ faço também a::

socialização de ideias $(+)$ com:: com eles $(+)$ e também $(+)$ eh::

a gente faz leitura compartilhada e algumas rodas:: de conversas né?

fazemos sempre algu::ma atividade envolvendo leiTURA e daí nós

eh $(+)$ investigamos um pouco mais a (+) compreensão textual

desses alunos através desses dessas dessas estratégias, né? Que nós usamos [...]

$\mathrm{Na}$ fala contida no fragmento 05 , a seguir, constatamos que o docente faz um breve relato sobre a forma como realizou atividade com o texto oral, ou seja, uma espécie de planejamento, contudo não percebemos a sistematização dos aspectos orais inerentes aos textos utilizados.

\section{Fragmento 05 - Ent. 02}

A gente trabalha a oralidade com com (+) eles é::

através de reCAdos (+) avisos que eles TRAzem $(+)$ de CAsa:: (+) do dia a dia deles $(+)$ do cotidiano existe algum outro::

eh:: como reportagens $(+)$ ou entrevistas $(+)$ ou /

$\mathrm{sim} /$ a gente trabalha também com reportagens $(+)$ que a gente $(+)$

recorta de jornais $(+)$ eles trazem alguma reportagem que eles escutaram $(+)$

ou $(++)$ jornais FALAdo ou escrito

e eles trazem na segunda- feira $(+)$ por exemplo $(+)$

a gente $(+)$ fala na sala $(+)$ conversa sobre $(+)$ os tipos de notícias bem $(+)$ a gente $(+)$ eh $(+)$ eles lerem/ ler o que o que viram $(+)$ e depois que eles lerem vão fazer tipo um debate $(+)$ entre eles $(+)$ dos assuntos do dia $(+)$ o que eles concordam $(+)$ o que não concordam 
com aquelas noTÍCIAS (++) do dia a dia deles

No entanto, não percebemos que o gênero debate tenha se tornado um objeto de ensino e aprendizagem propriamente dita, porque não houve a pretensão de explorar as características próprias pertencentes ao referido gênero, tais como: a definição clara dos objetivos da atividade, a seleção do tema, os papéis dos participantes (expositores e moderador), a posiçáo dos debatedores (a favor ou contra), a definição das regras do debate (tempo para cada expositor e ordem de apresentação). Além disso, não identificamos uma orientação aos alunos quanto ao aprofundamento do tema pela leitura de textos com pontos de vista divergentes, bem como a seleção do uso de registro formal, da prosódia e da gestualidade que, unidos aos aspectos linguísticos, contribuem para reforçar a argumentação na defesa do ponto de vista. Ou seja, o debate é concebido como uma conversa realizada rotineiramente na sala de aula. Vislumbramos que não houve a compreensão teórica adequada do docente para desenvolver atividades com este gênero oral.

De igual modo, o seminário, apontado como uma das atividades frequentemente trabalhadas, não atendeu integralmente às especificidades de uma prática pedagógica adequada, objetivando atender às especificidades deste gênero, haja vista que o professor não explorou as questôes sobre a definição do tema; a utilização de diferentes fontes de pesquisa; o planejamento das etapas; os papéis sociais dos envolvidos, seja na condição de expositor/apresentador ou de auditório, bem como as funçóes desempenhadas por cada um dos participantes. Porém, verificamos que o docente, pelo menos, procurou dar ênfase à questão da apresentação oral a partir da organização das falas dos expositores, uma vez que orientou sobre aspectos linguísticos comuns ao gênero seminário e quantos aos elementos paralinguísticos apropriados, conforme destacamos a seguir:

Fragmento 6 - Ent. 03

bom (+) o gênero oral que:: (+) priorizamos em sala de aula (+) é o gênero seminário $(+)$ é o que a gente mais trabalha $(+)$ a questáo da/ de o aluno justamente trabalhar:: $(+)$ a sua fala, né? Durante a apresentaçáo de um trabalho (+) não entregar só o trabalho escrito $(+)$ mas também ele saber apresentar $(+)$ saber falar $(+)$ o que estudou $(+)$ se ele realmente estudou ele vai saber falar né? e durante $(+)$ e durante esse(+) esse (+) gênero oral (+) a gente /duRANte as Apresentaçôes a gente faz as correçóes necessárias (+) de postura (+) de projeçáo da voz $(+)$ a questáo da:: (+) das pausas:: (+) quando ele está apresentando $(+)$ e com a gestualidade e posiçáo diante do auditório 
duRANte mesmo a (+) / não durante a apresentação para não atrapalhar nem inibir o aluno $(+)$ mas quando todos os grupos terminam de apresentar $(+)$ a gente faz essas correções no final

Notamos que o docente não assumiu uma postura de certo e de errado em relação às marcas linguísticas próprias do texto oral, produzido no momento da apresentação do gênero seminário. Ele apenas situou os alunos quanto ao uso adequado da linguagem para aquele contexto interacional. Apesar do esforço em trabalhar este texto oral, foi possível vislumbrar que não houve um planejamento sistematizado, conforme ocorreu no final de sua fala quando não explicita claramente quais os aspectos da oralidade irá observar no momento das apresentaçôes.

Quanto aos gêneros orais no formato de relato, entrevista, aula expositiva dialogada, jornal falado, entre outros, os professores entrevistados apenas afirmaram que os priorizavam em suas ações didáticas, mas não revelaram como têm tornado estes textos orais como objeto de ensino.

Vale salientar, nessa discussão, que apenas um dos entrevistados explicou de modo detalhado a metodologia que desenvolve para trabalhar com a oralidade, partindo de uma estratégia na qual salienta a importância dos textos orais, como indicamos a seguir:

\section{Fragmento 7 - Ent. 06}

para trabalhar com os gêneros da modalidade oral (+) geralmente utilizo $(+)$ algumas estratégias metodológicas $(+)$ como $(+)$ converso com a turma que os gêneros orais sáo táo importantes quanto os que priorizam a escrita (+) logo após (+) tento enfocar as situaçóes de uso daqueles gêneros e a estrutura tradicional deles $(+)$ em seguida $(+)$ tento partir para a parte prática $(+)$ ou seja $(+)$ eles produzindo $(+)$ fazendo uma situação comunicativa em sala $(+)$ ressaltando que essa última etapa acompanhada do contato dos alunos com a leitura para se ter a familiaridade com os gêneros

Quanto à produção de textos orais, as orientaçóes oficiais recomendam a realização de atividades em que os discentes tenham uma preparação prévia quanto à diversidade de usos de gêneros orais, comumente utilizados em situações do cotidiano.

É preciso destacar, também, que analisar textos orais, especialmente diálogos, constitui-se numa prática bastante proveitosa, pois, como a conversação é uma atividade de linguagem localmente ordenada, isto é, organizada passo a passo pelos falantes, favorece o entendimento dos alunos de que, no curso da 
interação, os interlocutores têm o direito à palavra, assumindo, papéis intercambiáveis de falante e ouvinte. Dessa forma, o professor estimula-os a falar e a escutar de modo organizado, porque, em conformidade com um dos princípios das atividades conversacionais e sociais, no diálogo, a regra estabelecida proclama "fala um de cada vez" (Sacks, Schegloff e Jefferson, 1974), ou seja, cada interlocutor tem sua participação através dos turnos de fala.

Nessa perspectiva, verificamos que alguns docentes salientaram que a realização de atividades pedagógicas com os textos orais deve elucidar questôes sobre os elementos organizacionais da conversaçãa ${ }^{1}$, quais sejam: turnos, tópicos, situaçáo, participantes, modo do discurso. No entanto, eles deram maior destaque aos fatores pragmáticos representados pelas pausas, paráfrases, hesitaçóes, alongamentos de vogais, repetiçóes, ênfases, truncamentos, marcadores conversacionais e aos recursos paralinguísticos, que exercem uma função relevante na conversaçáo, como podemos ver no fragmento a seguir:

\section{Fragmento 08 - Ent. 09}

acredito que os elementos da organizaçáo do texto oral que eu dou um enfoque mais significativo são as entonaçóes (+) o truncamento na fala $(+)$ as hesitaçóes $(+)$ a repetiçáo $(+)$ a náo conclusáo do fato narrado $(+)$ no momento em que os alunos se dão conta dessas características e de como fazemos uso constante desses elementos (+) os alunos passam a utilizar a modalidade oral já de uma forma diferenciada $(+)$ passando a utilizar a coesão e a coerência mais adequadamente

Conforme os docentes explicitam em suas falas, a relação fala e escrita é vista no sentido de que a primeira é um meio para viabilizar a segunda. Assim sendo, constatamos que há certa confusão teórico-metodológica, que nos faz vislumbrar a prioridade e o prestígio dados ao texto escrito e uma compreensão preconceituosa em relação à fala, tal como destacamos nos fragmentos abaixo:

\section{Fragmento 09 - Ent. 10}

as atividades orais servem de base para a escrita $(+)$ objetivando facilitar ao aluno $(+)$ a produção textual condizente com os propósitos do texto escrito $(+)$ desse modo $(+)$ propicia-se uma reflexão sobre essas modalidades a fim de que os alunos percebam as características que

1 As questôes sobre a organização conversacional foram fundamentadas nos estudos de Sacks, Schegloff e Jefferson (1974), Marcuschi (1986) e Jubran et al. (1993). 
são inerentes a cada uma das modalidades

\section{Fragmento 10 - Ent. 10}

levo sempre o aluno a refletir sobre a forma como se expressa e como sua fala reflete em sua escrita (+) fazendo- o observar que não deve- se escrever da mesma maneira que se fala (+) pois na escrita é preciso atentar para as normas e na fala náo

\section{Fragmento 11 - Ent. 11}

no nosso dia- a- dia nos deparamos com situaçôes em que o aluno às vezes fala da maneira que ouve na sua convivência diária $(+)$ e é preciso mostrar a maneira correta peço aos alunos que identifiquem os tipos de fala de acordo com o contexto (+) e indico leituras sobre o texto caipira e depois peço para que eles (+) reescrevam utilizando o dicionário.

Nesse sentido, interrogamo-nos como estes professores podem viabilizar práticas pedagógicas com textos orais se permanecem com a concepção de oralidade como espaço da desordem e do caos? Assim sendo, quando e como estes docentes irão torná-los objetos de ensino e aprendizagem, conforme sugerem as orientaçóes curriculares de ensino de Língua Portuguesa?

No fragmento 11, verificamos que, nas atividades de retextualização propostas, o professor acredita que o aluno deve privilegiar a norma culta padrão em detrimento das variáveis linguísticas, o que se constitui como um entendimento falacioso em relação à fala e à diversidade cultural.

Ao analisarmos as falas presentes no fragmento 12, a seguir, deparamonos com alguns depoimentos que nos causam estranheza e preocupação, haja vista que os docentes categorizam a repetição - elemento estruturador do texto oral - como "enfadonha", "desnecessária" e que "às vezes deixa o texto:: mesmo na oralidade, incompreensível”, sem se darem conta de que o seminário é um gênero da oralidade.

\section{Fragmento 12 - Ent. 07}

num seminário os alunos vão apresentar ...

assim anh:: $(+)$ eu procuro a sempre mostrar pra eles que:: $(+)$

às vezes a repetiçáo é desnecessária a partir do momento que há

no momento uma substituição $(+)$ por exemplo $(+)$ na:: $(+)$

aí entra a coesão né? (+) que a gente trabalha com anáfora (+) nunca

você fala para o aluno o que é uma anáfora (+) né? ele pode:: citar algo algo 
que foi citado $(+)$ que já foi dito $(+)$ com outro:: outro termo(+) [...] aí eu vou explicar pra ele que existe uma FORMA (+) de ser citado aquele TERmo (++) pra que náo haja essa repetiçáo que a repetiçáo se torna enfaDONHA $(+)$ as vezes deixa o texto:: mesmo na na oralidade incompreensível (++) se faz esse esse:: esse balanço (+) dessas repetições mostrando que existe ouTRAS FORmas e daí entra todo o processo de coesão e:: coerência né? é o sentido completo

Além desses aspectos, foi possível notar que faltam aos professores os conhecimentos teóricos sobre os quais poderiam desenvolver um trabalho profícuo com textos orais, bem como a organização didática das atividades de modo que fossem planejadas todas as etapas (preparação, execução e avaliação). Nesse sentido, eles levariam em conta os papéis dos participantes da interação, os usos da linguagem apropriados às situaçôes comunicativas, os aspectos da textualidade (recursos de coesão, coerência, intertextualidade, situacionalidade, informatividade, intencionalidade), o uso do registro formal ou informal e os elementos organizacionais.

Portanto, acreditamos que, se não houver a sistematização das tarefas com textos orais apoiada nas teorias linguísticas e didático-pedagógicas, será difícil viabilizar um ensino produtivo das habilidades orais, que atenda às orientaçóes didáticas da proposta educacional e dos objetivos de ensino de língua materna.

\section{CONSIDERAÇÓES FINAIS}

Nesta investigação, o nosso propósito foi refletir acerca da oralidade em sala de aula de Língua Portuguesa e o que dizem os professores do ensino básico. Com este objetivo, procuramos investigar se os textos orais estavam sendo utilizados como objeto de ensino no desenvolvimento de práticas comunicativas que pudessem investir na formação de alunos autônomos e competentes em diversas situaçóes de uso da língua.

Os resultados das análises dos dados, que coletamos através de entrevistas, revelaram que os docentes ainda não têm clareza das noçôes teóricas sobre a oralidade que os possibilitem realizar açóes didáticas canalizadas para a formação de alunos linguisticamente competentes. Entendemos, portanto, que os professores precisam ancorar suas práticas pedagógicas nos postulados teóricos que fundamentam a noção de língua socialmente concebida, o texto como lugar de interação social, considerando-se que tanto a oralidade quanto a escrita são modalidades de usos da língua merecedoras de igual atençáo. 
Dessa forma, no trabalho com a oralidade os professores precisam privilegiar os aspectos linguísticos, extralinguísiticos, paralinguísticos e cinésicos, propiciando aos alunos vivências em atividades pedagógicas que lhe sirvam de subsídios nas práticas sociais da vida cotidiana.

Além disso, compreendemos que os docentes realizam açóes didáticas no formato de um conhecimento tácito, tendo vista que desenvolvem práticas esvaziadas de aportes teóricos. Assim sendo, torna-se necessária a apropriação e o aprofundamento dos saberes sobre os usos da língua em diversas situaçóes comunicativas, incluindo-se aí a oralidade. Por fim, apontamos como imprescindível para o trabalho destes docentes o planejamento e a sistematização das atividades que possam desenvolver uma prática pedagógica significativa com textos orais.

\section{REFERÊNCIAS}

Bagno M. Preconceito Linguístico: o que é e como se faz. Sáo Paulo: Loyola; 1998.

Biber D. Variation across speech and writing. Cambridge: Cambridge University Press; 1988.

Brasil. Secretaria de Educação Fundamental. Parâmetros curriculares nacionais: terceiro e quarto ciclos de ensino fundamental: Língua Portuguesa. Brasília: MEC/SEF; 1998. Disponível em: < http://portal.mec.gov.br/seb/arquivos/pdf/portugues.pdf> Acesso em 14.12.2015

Castilho AT. A língua falada no ensino de Português. São Paulo: Contexto; 1998.

Cavalcante MCB, Melo CTV. Gêneros orais na escola. In: Santos CF, Mendonça M, Cavalcante MCB. Diversidade Textual: os gêneros na sala de aula. Belo Horizonte: Autêntica; 2007. p. 89-102.

Fávero LL, Andrade MLC, Aquino ZGO. Oralidade e escrita: perspectiva para o ensino de língua materna. 5. ed. São Paulo: Cortez; 1999.

Gomes-Santos SN. A exposição oral: nos anos iniciais do ensino fundamental. Sáo Paulo: Cortez; 2012. 
Jubran CCAS (Org.). Organização tópica da conversação. In: Ilari R (Org.). Gramática do Português falada. v. 2: Níveis de Análise Linguística. 4. ed. Campinas, SP: Unicamp; 1993. p. 357-447.

Kerbrat-Orecchioni C. Análise da Conversação: princípios e métodos. Trad. Carlos Piovezani. São Paulo: Parábola; 2006.

Leal TF, Goes S (Orgs.). A oralidade na escola: a investigação do trabalho docente como foco de reflexão. Belo Horizonte: Autêntica; 2012.

Leal TF, Brandão ACP, Lima JM. A oralidade como objeto de ensino na escola: o que sugerem os livros didáticos. In: Leas TF, Goes S. A oralidade na escola: a investigação do trabalho docente como foco de reflexão. Belo Horizonte: Autêntica; 2012. p. 13-35.

Lima A, Beserra N. Sala de aula: espaço também da fala. In: Leal TF, Goes S. A oralidade na escola: a investigaçáo do trabalho docente como foco de reflexão. Belo Horizonte: Autêntica; 2012. p. 57-72.

Marcuschi LA. Análise da conversação. São Paulo: Ática; 1986.

Marcuschi LA. Oralidade e ensino de língua: uma questão pouco "falada". In: Dionisio AP, Bezerra MA (Orgs.). Livro didático de português: múltiplos olhares. Rio de Janeiro: Lucerna; 2001a.

Marcuschi LA. Da fala para a escrita: atividades de retextualização. São Paulo: Cortez; 2001b.

Marcuschi LA. A oralidade no contexto dos usos linguísticos: caracterizando a fala. In: Marcuschi LA, Dionisio AP (Org.). Fala e escrita. Belo Horizonte: Ceale; 2005.

Marcuschi LA. Curso Fala e escrita. Material didático elaborado para o curso fala e escrita: característica e uso, oferecido no $2^{\circ}$ semestre de 2002; Programa de Pós-Graduaçấo em Letras e Linguística da UFPe. 2002. Mimeografado.

Melo CTV, Cavalcante MCB. Superando os obstáculos de avaliar a oralidade. In: Marcuschi B, Suassuna L (Orgs.). Avaliação em língua portuguesa. Belo Horizonte: Autêntica; 2006.

Preti D (Org.). Análise de textos orais. 7.ed. São Paulo: Humanitas; 2010. 
Preti D (Org.). Interação na fala e na escrita. 2.ed. São Paulo: Humanitas; 2003.

Preti D (Org.). Estudos de Língua Falada: variações e confrontos. 3.ed. São Paulo: Humanitas; 2006.

Sacks H, Schegloff E, Jefferson G. A simplest systematics for the organization of turn for conversation. In: Shenkein J (ed.). Studies in the organization of conversational interaction. New York: Academic Press; 1974. p. 7-55

Schneuwly B, Dolz J, et al. Gêneros orais e escritos na escola. Trad. Roxane Rojo e Glaís Sales Cordeiro. Campinas, SP: Mercado das Letras; 2004.

Sgarbi NMFQ. Os eventos da oralidade no ensino de língua portuguesa. Revista Trama. 2008;4(7):167-175.

Silva LA (Org.) A língua que falamos. Português: história, variação e discurso. São Paulo: Globo; 2005. 